Tratamento : intervenção cirurgica.

A intervenção não foi praticada porque o doente ao seber que ia ser operado pediu licença para consultar a familia, sahiu e nunca mais voltou.

Concluimos esta observação dizendo que :

$10^{\circ}$ - o nosso doente é portador de uma epilepsia parcial, Bravais-Jacksoniana, typo brachio-cervico-facial;

2.c - esta epilepsia é devida a uma lesão localisada na região das circumvoluções motoras frontal e parietal ascendentes do hemispherio esquerdo, não tendo attingido o lobo paracentral;

$3 .^{\circ}$ - a lesão consiste numa depressão da aboboda craneana situada na região fronto-parietal esquerda;

$4 .^{\circ}$ - a therapeutica é cirurgica.

Publicamos este caso apparecido no serviço do Professor Rubião Meira, de que somos interno, por não ser muito frequente e para frisar a localisação da lesão em contraposição com a epilepsia essencial, cuja pathogenia é ainda objecto de estudos e cujo tratamento cirurgico preconisado por Championniére não tem conseguido senão dissabores aos que o tem praticado.

S. Paulo, 28 de agosto de 1920 .

JOAQUIM PENNINO

\title{
Conferencia realisada em Pirassununga
} PELO DOUTORANDO POTYGUAR MEDEIROS

Os doutorandos de medicina, da Faculdade de S. Paulo, gulados pela Missão Ro'kfeller empenham-se actualmente em uma campanha de saneamento do nosso Estaido. Eis como eu vos explico a minha presença entre vos.

Pelas principaes cidades paulistas, por toda's quantas representem nucleos de irradiação de progresso para outras menores, principalmente naquellas onde houver Escolas Normaes para preparo de professores far-se-á ouvir, quando ainda se não houver feito, a voz dos estudantes da sciencia abençoada.

Contamos, os meus distincto's de lucta e eu, que dupla resultante se seguirá ao nosso gesto; primeiro, um resultado immediato, symibolisado pela consideração que fôr tributada aos nossos conselhos por parte dos poderes publicos, das aggremiaçoses escolares e até directamente, sem a interferencia destes seus representantes, pelas populações cidadans e ruraes: resultará ao depois, esperamos, a reproducção do nosso esforço por outras pessoas de outros Estados da União, visando, como 
nos visamos, a extinç̧ão de certos males que infelicitam, que desgraçam inactivando uma legião de brasileiros, varios milhões de pobres individuos a que nos sentimos irmanados pelo vinculo sacratissimo de Patria.

Cheios de esperança, confiantes na identidade de sentir dos nossos compatriotas sadios, luctamos e luctaremos sempre, sem rebuços, pela julgação, pelo aniquilamento de estados morbidos, cuja existencia não se explica nem se desculpa em regiões ricas como as nossas, entre um povo jovem como é equelle a que o nosso bom destino quiz que pertencessemos. Anhelamos a emancipação, de muitissimos patricios nossos, da formidavel Bastilha, do jugo ferreo que o ancylostomo e o necator, o plasmodio, o trypanozoma o treponema, o bacillo de Koch e o de Hansen, lhes constroem escudados na sua ignorancia e acolytados pelo abuso do alcool a que se entregam as desiditosas victimas. Todos estes males existem em toda a parte, em to'dos os paizes em quasi todas as cidades; mas não é isto razão para que não tratemos de os combater sem treguas, tanto mais quanto, entre nos, as suas proporções são avantajadas e, consequentemente, seus damnos, quando não irreparaveis, são descommunaes.

A tarefa é pesada e vae ser longa; mas não vemos nisto motivo para que não a prosigamos, para que suffoquemos os impetos caritativos e patrioticos dos nossos corações: para nós não ha, na extensão do tentame, justificativa para a destruição do ideal que transportamos em nossas almas, qual o de um dia sobermos forte e productivo o grande povo da mais rica terra sul-americana.

Não nos impacienta, como não nos detem, a espera, que nos é imposta por multiplas circumstancias, da realisação do que ideamos hoje.

Auxiliae-nos - e eu venho solicitar o vosso auxilio - e teremos garantido a sazão dos fructos que sie colherem do nosso patriotismo, arvore preciosa que, amorosamente, como os nossos antepassados e como v6s outros, alimentamos com o nosso trabalho e fortalecemos com as nossas carinhosas esperanças.

Muito se tem dito sobre o estado sanitario do Brasil; pouco se tem feito em prol da sua melhoria. Entre quantos hajam luctado para arrancar a nossa gente ás unhas lacerantes de males antiquissimos, figura, em notavel relevo, a Fiundação Rockefeller, derivantte bendicta de uma grande fortuna, fructo carissimo, inestimavel, de uma philanthropia maior do que os haveres do seu portador - Rockefeller, poderosissimo industrial norte-americano que, condoido da miseria physica em que muita gente vive, comprehendendo que para si, para o seu viver desejado, era excessiva a messe de recursos á sua disposiçāo, repartiu-a com aquelles a quem nem a felicidade da saude tremeluzira no horizonte da vida. O ouro do millionario faz o milagre, sem noticia até aqui na historia humana. dos cofres, para onde o canalisara um trabalho ingente, espalhou-se para os laboratorios onde se pesquizam as doenças mal conhecidas, para as salas de autopsia, onde se descobrem lesões ignoradas do organismo do homem, para os hospitaes, onde re combatem os males infelicitadores das familias, depauperadores do povo, destrutdores das raças e das nações.

Entre nos a Fundação Rockefeller age principalmente contra a necatorose ou uncinariose. Os resultados esperados já começam a apparecer e despertam nos brasileiros de brio civico a idéa de que a instituição americana vale tanto por seus piedosos trabalhos quanto por seu 
immarcescivel exemplo. Prova disto nol-a dão alguns governos determinando os serviços de saneamento rural.

Sem que nos esqueçamos da benemerencia da Fundação Rockefeller. sem que ousemos negar os beneficios que ella espalha sem pedir retribuição, não nos inquerimos sem um certo constrangimento, sem uma tal ou qual tristeza, da razão porque o saneamento, pelo menos de São Paulo, deixa de ser feito totalmente pelo proprio Estado.

São Paulo, pelo menos São Paulo, deveria, no Brasil, prescindir em favor das regiões menos abastadas do auxilio que lhe presta a caridade norte-americana.

São Paulo é bastante rico para que não possa dispender a somma exigida pelo serviço de prophylaxia e cura dos seus flagellos morbiajos, unicas desditas que se lhe apontam e unicos obstaculos que entravam sua marcha pela estrada de progresso que todos nos desejamos perlustrar.

Para attrahir sobre este facto a attenção dos seus coestaduanos é que os estudantes de medicina se promptificam a percorrer as principaes cidades do Estado, reeditando as ideaias dos seus Mestres, re:terando conselhos e ensinamentos a favor da saude publica, confiantes no successo do seu labor.

Pirassununga é a 2.a cidade visitada pelos academicos da Faculdade de Medicina; ja o foi São Carlos e muitas outras ouvirão o appello identico dos meus distinctos collegas de Esicola e irmãos de culto á Patria.

E' um meio de educação do povo, este de se lhe fallar, porque, ao contrario do que parece, fica sempre, se não de todo, uma parte do thema, fujam emibora rapidas as reminiscencias da palavra.

Não basta, porém, a prescripção; é indispensavel a realisação do plano, é mister a conicretisação do projecto, com tanto carinho elaborado no coração, traduzido pelo cerebro e proferido por bocca em que sర6 a morte calará a glorificação da nossa nacionalidade e a inśtigação ao aperfeiçoamento das nossas olbras que, não podemos consentir, se mantenham aquem da belleza do nosso passado.

Mas o nosso povo ainda não está inteirado, ainda não se aperceberu do quanto ha de grandioso na aoção que se intenta, desde ha algum tempo, em beneficio de sua saude, em favor da sua vitalidade.

Ainda não ouvio o bastante para se convencer da necessidade que ha err augmentar o seu proprio interesse pelas cousas que se the diz.

Por outro lado, não as comprehende porque carece de instrucção, porque the falta o conselheiro desinteressado em quanto seja secundario; porque the sobra o charlatāo, o curanideiro astuto; porque nāo conhece de politica nada alem da posse da victoria, nāo sabendo aproveital-a, ou o dissabor da derrota, desconhecendo como remedial-a.

Não obstante, é o brasileiro um povo de caracter hygido, e,embora, por indole, pouco expansivo, traz comsigo noções elevadas de amor patrio e concepcões assaz lisongeiras ácerca de dignidade nacional e brio pessoal.

Não fôra a tempera dos seus filhos e o Brasil, em 18.22, ao se libertar da tutella portugueza, haver-se-ia fragmentado, como aconteceu com a America Hespanhola, e não seria hoje, depois de tantos e tão variados governos, a nação intacta, limita'da pelos seus primitivos limites. Por amor á sua terra o povo a conserva como a recelbeu dos seus ancestraes e nāo quer ouvir nada que lhe falle de desmenbramento.

Este caracter é, sem duvida, de alto valor moral e muito recommenda áquelles que o possuem e o cultivam.

E' moda hoje fazer-se a analyse caricatural, a critica humoristica dos 
brasileiros, por patricios seus, quando mesmo não se percebe a sua feitura pela ousadia de certos extrangeiros.

Concidadãos nossos pintam o nosso sertanejo sob um aspecto exclusivamente vegetativo, tendo, dizem elles, somente funções da vida animal; respira e tem circulação, digere e tem faculdade de eliminar os productos residuaes das combustões organicas... A vida cerebral, accrescem, como a cerebellar, não existe no brasileiro do sertão; elle não produz alem do necessario á sua subsistencia por tempo limitado. Obtida a ração, volta ao 'deścanso e nelle permanece até qque se sinta physiologicamente obrigado á trabalhar. Parece-me que não é tanto assim. O brasileiro, sujeito ao clima das regiões tropicaes, menos favoravel que o das outras zonas, soffre a sua influencia, mas, para que tal soffrimento se dê, não é preciso ser-se brasileiro; outro qualquer povo, qualquer outra raça soffreria do mesmo modo e não seria povo ou raça de maior actividade apparente. Aos desfavores climatericos reunem-se a ignorancia e o alcoolismo que, mal entendido pelo povo, este não o vê como prejuizo antes de ser, como parece, estimulante.

Por mais de uma vez se ha censurado no caboclo o facto de não ser patriota, de ser vadio. Mas, pergunto eu, qual é a sua iculpa? A de haver nascido em um terreno que se pode chamar "neutro", limite entre a "anima vili" e a "anima nobili"? Porque elle nasceu e, por certo, viverá e morrerá mantendo apenas contacto ligeiro com os seus semelhantes mais ou menos civilisados?

E' no sertão de difficil accesso, semi-virgem que nascem milhões de brasileiros, não contando com escolas para a desbravação de sua intelligencia, não possuindo estradas que o approximem dos seus visinhos, entregues, como estes, ao instincto de conservação da vida pelo aproveitamento facil das dadivas da natureza.

Longe da civilisação, desamparados de todo, os pobres homens são obrigados a viver por si, para si e comsigo. Culpamol-os depois, censuramos e ridicularisamos o seu "modus vivendi", esquecendo-nos de que os unicos culpados somos nós, que sabemos lêr, que temos noções superiores da vida, que vivemos nos centros de maior perfeição, que sabemos da sua existencia miseravel e os abandonamos e os olvidamos, s6 ros relembrando de suas bisonhas pessoas quando queremos fazer humorismo á custa de suas desgraças encarando-as sob caprichosas formas litterarias, considerando-as factos de muito chiste. Depois... deixamos o sertanejo passando os seus tristes dia sob o tecto esburacado de sua misera palhoça barreada, cercádo de sua esqualida mulher - valente procreadora - e de seus pobres filhinhos, projectos, por nós, approvados de futuros homens iguaes ao pae. Depois de nos rirmos bastante da "philosophia" do caipira, largamol-o a gastar sua energia, que vale tanto quanto a nossa, no cultivo antiquado dos campos, no empenho de rudimentares industrias, sem uma orientação, sem um livro, sem uma escola que o beneficie.

Nós, os moradores da cidade, quasi nada havemos feito em favor dos nossos bons concidadãos do interior. E' preciso, se não quizermòs vêr a ciecadencia proseguir sem cessar, que cuidemos mais de nossa gente, instruindo-a, elevando-lihe a alma de nobreza latente, conduzindo-a para junto dos seus compatriotas mais felizes e mais cultos.

A officina onde se realisa esta obra miraculosa chama-se escola. Encaminhemos o caipira para ella e em pouco veremos della sahir um individuo igual a qualquer um de nós. Nas cidades mesmo, nos cantros mais populosos, onde as escolas não são muito deficientes em numero, são muitos, muitissimos os homens de intellectualidade inferior por falta somente de lapidação. E' commum encontrar-se a gente com ra- 
pazes sadios, trabalhadores, de bons sentimentos mas, analphabetos ou quasi assim. Em São Paulo, capital do Estado mais importante da União, o operariado, a iclasse dos serviçaes, os empregados de pequenas e grandes industrias, sāo muito rudimentarmente instruidos. Quando meninos, aos 7 ou 8 annos, são enviados á escola primaria, de onde saem aos 10 annos para o trabalho, sem que nunca mais cogitem de educação.

Eu ainda me recordo, e nunca mais me esquecerei, da desoladora impressão que recebi, numa cidade do interior onde auxiliei a combater uma epidemia grippal, quando, em uma casa, distante menos de um kilometro da escola primaria, deparei com 23 pessoas, de uma mesma familia, 11 das quaes em idade escolar e todas analphabetas. Havia velhos, moços e creanças, todos sem poder sequer lêr o rotulo dos medicamentos que, por isto vinham assignalados com cruzes cujo numero correspondia ao de outras, rabiscadas a cabeceira de cada um dos 8 doentes.

Allegavam os chefes da casa que, no Grupo Escolar, não haviam encontrado lugares para os seus meninos.

No tempo de Sparta, quando as conquistas se faziam a golpes de astucia e de força, quando a coragem physica era considerada maximo valor do homem, os cidadãos tomavam de seus filhos, quando estes completavam 7 annos e os entregavam á Nação para que ella os fizesse bons soldados, isto é, segundo o criterio da epoca, cidadãos perfeitos. Dos 7 annos em diante os spartanos pertenciam ao Estado, o que vale dizer, se pertenciam mutuamente.

Hoje, que tudo se faz segundo os conhecimentos humanos, que a forca intellectual sobrepujou a força material, não se admitte que possa alguem viver sem ella; e nós permettimos que 70 olo dos nossos concidadãos ignorem até as lettras do alphabeto, deixamos que mais de 20 milhões de brasileiros sejam inuteis a si a.os seus, toda vez que se lhes solicitar o emprego das faculdades intellectuaes adaptadas á epoca!

Porque se não ha de fazer obrigatorio o ensino primario em toda a Republica?

Porque não, se é este o unico recurso para se exterminar a desgraça que é a ignorancia, se é este o unico meio de se impedir que, por descuido ou desleixo de seus paes, milhares e milhares de creanças percam sua intelligencia, deixando-as submergir na irracionalidade dos demais seres vivos da natureza, até o dia em que, tornando-se paes ellas comm.ttam o mesmo crime de que hoj sāo imbelles victimas ?

A campanha contra o analphabetismo deve preceder, deve ser o preambulo de todas as outras. De quanto nos servirá pregar a prophylaxia rural, se os rusticos não nos podem comprehender; os nossios conselhos nāo chegarāo directamente até elles. Vơs, pelo menos actualmente, sereis obrigados, se quizerdes cooperar comnosco, a empregar recursos varios, verdadeira mnemonica, porque o pobre analphabeto não poderá tirar, por si, illação do que the dissermos.

Para fazer cessar este hediondo estado de miseria intellectual, para se arrancar estes milhões de desventurados ás garras, aos tentaculos inhibidores da bruteza de espirito, para se não perder esta legião de soldados que o nosso progresso está a pedir, é preciso um esforço herculeo de vontade e de tenacidade, que só um acrisolado amor á terra natal poderá gerar e sustentar.

A iniciativa particular não basta, porque não pode dictar e fazer cumprir leis; as Municipalidades, associadas aos governos dos Estados e da União, devem decretar a obrigatoriedade do ensino primario, como medida primordial para o saneamento popular como condição essencial para a comprehensão, por parte do povo, das regras imprescindiveis ao melhoramento do seu viver. 


\section{IN VINO SALUS}

E' a grande mentira que traz um formidavel contingente para a degradação sanitaria do nosso paiz. O alcoolismo é a praga que devemos exterminar para que o physico, o moral e o intellecto do nosso povo não desçam aos abysmos onde nāo ha a luz da vida, onde o homem se confunde ao animal por elle mesmo chamado inferior, onde se perde a esperança, onde a alma desapparece; que é o peior do que a sepultura porque nelle, no barathro da embriaguez, o individuo se precipita sem levar ao menos a saudade dos seus em lugar da commiseraçāo geral.

Aos bamboleios, aos tropeções, o olhar emparvecido e esgazeado, a bocca desgovernada, trazendo pendurado um riso embrutecido de escarneo e desespero, quantas vezes nāo viste, o pobre ebrio, moço ainda, deixando transparecer a perdida fortaleza, outrora, se bem guiada, capaz de produzir bom trabalho.

A idesgraçada victima ido alcool, ou, maís cento, o desgraçadio que se victimou pelo allcool, habituou-se a belber sem disto se apereceber; não tinha noção isegura do que praticava, porque a seduicção alcoolica era grande e o conselho que talvez houvesse tentado desvial-o foi, proporcionalmente a ella, demasiado pequeno; habituou-se a beber, sem o sentir, gradualmente, alegremente.

o que hontem the era olbjecto de idesfastio ou de prazer, ide passiatempo reputado inoffensivo nas rodas amigas, é hoje, para elle mesmo, uma necessilda'de organilca, premente como a alimentação ou o soimno.

O ébrio nāo póde, nāo consegue viver fóra do estado de sub-lconsciencia quie the cria o allcooll; não the agralda a perdia da semi-anesthesia que lhe proporciona o veneno ethylico. Parece que as sensações da rvida, as boas e as más, são, para elle, muito fortes e não podendo dellas escapar, - porque vive - procura sentil-as atravéz a intoxicaçāo amortecedora. Esta, cada vez mais, precisa ser mais intensa para produzir phenomenos de intensidade igual aos precedentes, porque a todas as excitações o organismo responde com realcções equivalentes, e o allicool lé um excitante.

Af lucta consitanite, os lataques crescentes, a penda continua ida energia vital, a defesa organioa amenorada a cada instante, determinam a vulnerasão do terrono em que ise passam - a morte prematura do alcoolista.

Em pouco tempo morre quenr fooi para a solcieldade um perigo, para os filhos um castigo, sem que nenhuma retribuiçāo thes desse, como os demais membros da collectividade o fazem.

Mas não lé ıś́ a ingestão ıdes:egrada đe alcool que mata; o bebericar, o belber lcalcallado, regraão aols calices ou aos copos, ás tiaças ou aos "martellos", stambem mata e antes de matar faculita a beibedor mais occasiões de prejuldicar aols seus circumsitantes, porquie antes de elle morrer, vieram os filhos taraudos, houve as idissenções na famiiia, os ataques a segurança peisiscal, o desvanecimento, a perda do socego lae muita senite. Os fillhos dos alcoolicos, na quasi totalidade, são individuos propensos ao allcoolismo; junte-se á herelditariedade, a allimentiasão incoonveniente que lé commum nas cliasses baixas, addicione-se a isto o máo estado de saude moral formado pela libertaçăo dos insitinctos e se terá o scenarto optimo para o desenvolvimento da grande idesgraça multisecular.

Entre o nosso povo, entre as classes abaixo da mediana, onde a 
educaçāo social e a educaçāo intellectual sāo rudimentos, miniatunas do que deveriam ıser. o uso do ellcool já não espanita senão áquelles que olham para o fuituro :da Patria !

E' a aguandente, é a fiamigeraiaja cachaça, o veihiculo malditicto que transporta para os presidios, para os manicomilos ou para as negras regiões ida esitupidez, ida bruteza de sispirito, a massia enorme de gente que bem ise aproveitaria se della ise livrasse.

o misero viciacic belbe, para se refrescar, quando o sol caustlica; quando, ao contrario, a chuva desice ou cahe o nevoeiro, o bacchico bebe para inão ise endeflluxar. Allcool é éperițivo antes ida comida; é para ella acompanhamente, solb forma de vinho iou ide cerveja; termina-a, depois ldo café ou ldepois da isoibremesa, feito llicor.

Belbem os homens e as muliheres! Eisitas, - supponihamol-as mães - ignorando que o alcool ingerido se elimina pela seicreção lactea alem de pelos emunetorios geraes, ignorando mais o effeito nefasto üo a!lcool sobre o organismo do labotante, lbelbm-n'o sem menhum escrupulo. E' imesmo corrente entre muitas idellas que a cerveja augmenta a quantida'de e imellhora a iqualidala do leite. Crentes na sabedoria popular (sabedoria lde analphabeto), ulsam de cerveja com

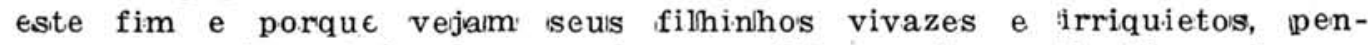
sam que este estado decorre de uma bôa sauide prolduzida pela excellencia da allimintação, revigoriala pela cerveja.

Engano! 10 leite ldas bebeldoras ide cerveja, secretaldo jla allicoolisaldo emlbriaga a creança, provolcando-lhe a excitação que tanto agrada á vista.

Mais tarde, porem, ao ser desmamado, o desiditoso pequeno isoffrerá, ao laado de pertur|bações Igasitro-inteistinaes, outras, lde orldem nervosa, por the faltar o estimulante que, nos seus primeiros tempos de vida, fôra-lhe propinado seguida, disfarçada e inconscientemente.

Mais tande, na mocidade, por 'ảeficiencia de educação, Isem o conseliho idomeistico que o afasite läras cormpan'hias perniciosas, ás vezes ampara:do pelo mía exempllo paterno, appareice, ma arena da degradação, mais um actor da tragedia alicoolica.

Quando não é protagonista de um idelicto, de um crime, quando não é um allienałı, é o comparisa de intelligenicia em/bruitecida, de exisitencia inutill, limproductiva loul lcrimlimosamente produlctora ide uma descendencia mevropatha, prediposita, ina 1.a infancia a menin. gite, ás iconvulsões, e mais tarlde, la tubericulose, a idesiquilibrio mental, ao proprio alcoollismo e ao crime.

Quando mesmo nāo seja nos dramas provocaidos pela intoxicaçāo ethylica nem comparsa secundario, é o misero, um espectador aparvaihado, desentendedor idos espectaculos lda vida Icommum.

Ao mesmo tempo que o alcooll produz ois seus nolcivos effeitos, agindo directamente, como causa, é concorrente, lé complemento de causas outras da desgraça humana.

E o abiuso do a!oo'l persisitindo, sem medida que o apoie, sem applicaçāo de lei que o reprima, em alguns annos destrāe, faz desapparecer uma geração depois de a haver feito desicer aos cambaleios os degraos da escada da vida, depravando-a gradativamente, pervertendo-a sem cessar.

Nós nāo temos estatisticas completas nosologicas e especialmente criminaes solbre o alcoollismo, mas, calculos isolaldols têm dicto que como em Plaris e em Vienna, onảe se bebe desmedildamente, 30 o o o Ċos nossos alienados sāo loucos alcoolicos; nos restantes 70 olo podemos garantir pel) menos em sua grande parte, o alcoolismo foi concausa. 
As nossas estatisiticas demographo-sanitarias são ainda muito falhas para que nos possam dizer quantas das pessoas mortas por affeções intestinaes, hepaticas, renaes, gatricas, arteriaes e cardiacas foram victimas directas ou indirectas da intoxicação alcoolica.

Urge, meus senhores, que combatamos o alcoolismo que, entre nos já se faz notavel. Praticae e apregoae a sua repressão real, systematica e incessante. Os actuaes beibedores inveterados, clamarão, se revoltarão agitados pela falta ou pela diminuição do toxico indispensavel ao seu deploravel estado geral. Gritarão os viciados de hoje mas, amanhã, educaldas sob a affirmação de que não é natural e é presicindivel o uso das bebidas espirituosas, as gerações vindouras viverão normalmente, em uso pleno das suas faculdades de intelligencia e do perfeito funccionamento de todo os seus orgãos, proveitosas para si e para os seus, para a familia e para a Patria. Não vos entibie a extensão da campanha, não vos atemorisem os protestos que se levantarão, porque, a medida que caminhardes, aquella decresicerá e estes se apaziguarão, transformando-se em outros tantos applausos e auxilios.

A' Municipalidade cabe a determinação das medilas necesisarias á extinçãa do mal. Lance sobre o alcool de bebida, qualquer que seja a sua forma de preparação, um imposto elevado e annualmente crescente, de maneira que se difficulte cada vez mais a sua acquisição: diminua ao minimo o imposto do assucar e do alcool desnatura'do, fabricado para a industria: taxe elevadamente as casas vendedoras de bebidas alcoolicas, de modo a entravar a su diffusão; proteja, alliviandothe as taxas, a venda de bebidas sem alcool, como o leite, xaropes, succo de fructas, etc. Estabeleça nas escolas, nos theratros, nas officinas, em toda a parte, por meio de livros, de jornaes, de cinematographo, conferencias, propaganda tenaz contra o alcoolismo. Institua ou contribua para a instituição de asylos e colonias para bebados habituaes, onde, como se faz nos hospicios de alienaidos, a pedido de suas familias ou das auctoridades, elles possam ser seigredados da soiciedade por tempo indeterminado e reeducados, regenerados por meio de conselhos e de trabalho.

Esta, meus senhores, derve ser uma attribuição das Camaras Municipaes, que, em congresso, facilmente poderiam resolvel-a e proporcionalmente cumpril-a, auxiliadas e orientadas pelo poder estadual.

\section{UNCINARIOSE}

E' a molestia nacional em voga; digo nacional nāo porquc seja endemia só brasileira, mas, porque das nossas molestias ella esteja em foco mais proeminente do que as demais. E' universal; a uncinariose espalha-se por extensas regiões dos cinco continentes; na America, onde ha zonas atacadissimas por ella, o Brasil é citado ao lado das Guyanas e das Antilhas como região mais infestarda.

E' uma affecção produzida por dous generos de vermes, da familia dos estrongylideos, da ordem dos nematodes, da classe dos nematelminthos - o ancylostomo e o necator - O Ancylostomo, que tambem é conhecido pelo nome de uncinaria, differe do necator por varios caracteres morphologicos e é chamado ancylostomo, por apresentar, na bocca, dentes em forma de ganchos (do grego, ankylos-gancho, stomabocca).

Verme cylindrico, branco, - rosado, afilado na sua extremidade anterior, onde apresenta a capsula buccal provida de dous pares de dentes ganchosos (dentes ventraes), duas pontas e uma lamina na face dorsal ia capsula; esta lamina cortante, que provem do pharynge do vor- 
me, é adherente, soldada á capsula e não é, por isto, saliente. O ancylostomo macho mede geralmente um centimetro; a femea, um pouco maior, chega a medir um e meio centrimetros. A extremidade posterior do corpo do macho tem a forma de um sino, é dilatada, emquanto que a da femea se afila caida vez mais, até se terminar em ponta. $O$ ancylostomo e provido de glandulas particulares, de cuja importancia eu vos fallarei mais adeante, e que se extendem nos dous terços anteriores do seu corpo. Reproduz-se por ovulaçāo; os seus ovos, de forma elliptica, medem $60 \mathrm{n},(60$ millesimos de millimetros) de comprimento por 40 a de largura. Dentro do ovo encontram-se, no momento da postura, 2 a 4 blastomeros, pequena's cellulas que, no decorrer da evolução do ovo, se segmentam, se subdividem. O verme vive no intestino delgado da homem principalmente no duoldeno, donde o nome de ancylostomo duodenalis, dado á variedade humana do ancylistomo. Os ovos são postos no intestino e depois acarretados para fora, pelo conteudo intestinal. Nāo se desenvolvem no interior do intestino porque ahi --a temperatura ambiente é muito levada, é desfavoravel $\left(37^{\circ}\right)$ e os gazes locaes não permittem que tal evolução se processe. Chegado ao meio exterior, encontrando oxygenio e uma temperatura humida como a do intestino porém menos elevada do que ella, o ovo se desenvolve; os blastomeros se fragmentam muitas vezes e em 24 horas o embryāo está formado; - é a larva rhabditoide (do grego, rhabdos-estriado, listado).

Cinco dias mais tarde, depois de algumas modificações morphologicas, quan'do então a larva cresceu de $200 u$ que media, a $500 u$, chega ao 2.o estado, que é o de larva estrongyloide encystada (strongylo, do grego-cylindro). São estas larvas encapsuladas as propagadoras da molestia; ellas é que nos devemos combater ao mesmo tempo que curamos os opilados, os individuos já adoecidos. A larva estrongyloilde encystada é muito movel, podendo, por si mesma, deslocar-se sobre o chão, subir aos barrancos e ao tronco das arvores, onde as mãos ou os pés descalços do homem a vão encontrar.

Ella penetra quasi sempre, senão sempre, pela pelle, como foi demonstrado por Looss, depois de haver sido casualmente infestado, quando trabalhava no seu Laboratorio.

O caso é que, Looss, manipulando uma cultura de ancylostomos, onde havia um grande numero de larvas estrongyloides encystadas, cahiram-lhe sobre a mão algumas gottas da cultura e elle, ignorando ainda a via de penetração dos ancylostomos, não se importou com o facto. Pouco depois, alguns minutos mais tarde, sentiu, no ponto attingido pela cultura, um prurido muito intenso e, inspiradamente raspou a pelle da região, examinou-a e verificou que apenas as capsulas das larvas permaneciam, estas já havenido atravessado a pelle. Tres mezes depois, em Looss, appareciam os primeiros symptomas da molestia.

Dahi por diante fizeram-se muitas experimentações, fi.cando cabalmente provado que a via de penetração do verme causador da uncinariose, por suas larvas de 2.0 estado, é a pelle, é a via cutanea. Entre as experiencias feitas, ha as do Prof. Austregesilo, da Faculdade de Medicina do Rio de Janeiro, em estudantes seus alumnos que a isto se prestaram, tal como o fizeram Grassi e seus discipulos.

Durante muito tempo nāo se soube como, atravessando a pelle, poldia a larva estrongyloide do ancylositomo chegar ao duodeno do homem. Foi o mesmo Looss quem conseguio aclarar a questão, resolver o problema que ameaçava abalar sua primeira theoria, a doutrina da infestaçāo cutanea da ancylostomose.

Em 1903, este scientista, no Congresso Internacional de Zoologia, realisado em Berna, mostrou, por meio de curiosas preparações mi- 
croscopicas, as provas do trajecto da larva ido ancylistomo, deside sua penetração pela pelle, até sua fixação no primeiro tracto intestinal. Vio-se então que, as larvas, ahegam ás veias da pelle, por ellas vão ás cavidades direitas do coração, passam, dahi, pela arteria pulmonar, aos capillares e alveolos do pulmão, lchegam aos bronchios, delles passam para a trachéa; deste conducto aereo, vão ter ao pharynge, de onde descem, impellidas pela deglutição de saliva ou de alimentos, para o esophago, depois para o estomago e por fim para o intestino, onde se localisam. As provas dadas por Looss foram confirmadas por muitos experimentadores e hoje são acceitas lcomo expressões da realidade.

Todavia, directamente pela bocca ou indirectamente pelos pulmões, por via da respiração, as larvas ido ancylostomo podem chegar ao duodeno. Pela respiração, o trajecto é a ultima metade do trajecto já descripito; "per os", pela bocca, a entrada se faz miediante a ingestāo de alimentos poluidos por mãos sujas de terra, como é commum ver-se entre trabalhadores, ou pela ingestão de agua contaminada por larvas do verme. Parece entretanto que antes do trabalhador poluir seus alimentos com as mãosi... já as larvas por ella mesma penetraram, porque este curioso phenomeno de entrada exige para a sua realisacão, apenas quatro minutos.

Pode-se affirmar que o meio commum de infestaçāo do homem, quanto á ancylostomose, é por travessia das larvas atravéz a pelle da planta dos pés de quem ande descalço sobre o chão onde algum indivlduo, portador da molestia, defecou, ou sobre o solo, para onde as aguas pluviaes carregaram fezes contaminadas expellidas em lugar mais elervado.

De 60 a 100 dias depois da chegada da larva ao instestino, o individuo começa a se sentir doente; ja a larva se desenvolveu, de ha muito, já é o verme adulto e nas dejecções do seu portador encontram-se os seus ovos, promptos para uma evolução identica á descripta.

Os vermes fixam-se ao intestino, por meio dos seus possantes dentes ganchosos, laceram a mucosa, o revestimento interno intestinal com as suas laminas 'cortantes e se nutrem, não de sangue como se pensou, mas dos retalhos, dos fragmentos roubados ao orgão onde se localisaram.

As feridas assim produzidas, pelas aceradas laminas de corte, sangram durante muito tempo, porque as glandulas cephalicas, de que vos fallei, secretam um liquido que tem a propriedade de impeldir a coagulação sanguinea. Por estas feridas é possivel a invasão do organismo por bacterias intestinaes, produzindo-se então, uma septicemia, uma infeç̧ão bacteriana generalisada, estado morbido, diverso e de gravidade immediata superior a da uncinariose.

$\mathrm{Na}$ verminose por ancylostomos o paciente queixa-se de dôres epigastricas, de fortes dores de estomago, que se exacerbam á pressão e a locomoção e que se amainam ap6s a ingestão de alimentos. Isto explica porque o opilado, não tendo vontade de comer, ingere sulbstancias alimentares e até outras que o não são, como terra, fragmentos de madeira, ou, como já se vio em um hospital, o prato lde barro da moringa de agua. Além das dõres na região do estomago, ha febre frequente, irregular, ‘dôres de cabeça, desarranjos gastro-intestinaes e, ás vezes, erupções cutaneas.

Ao fim de algum tempo, que varia com os individuos, ás perturbações de estomago e de intestinos, vem se sommar uma anemia progressiva que indica um estado avançado da molestia.

O infeliz'pende as côres das mucosas; a pelle macilenta parece uma crosta de cera ordinaria e poreja um suor algido e inquietante. As fa- 
ces se tumefazem, os pés incham, augmentam de volume pelo edema que sobe delles até ao joelho, marginando a crista tibial. A anemia, cuja causa Alessandrini, em 1904, imputou á uma substancia destruidora do sangue, á uma substancia hemolytica, - a mesma que impede a coagulação sanguinea das feridas da mucosa intestinal, - secretada pelas glandulas cephalicas e pelas glandulas cervicaes do ancylostomo, a anemia, provoca um enfraquecimento profundo do doente, que, ao menor esforço, ao esforço de andar apenas, se estafa, sente oppressāo, as pernas tremulas; os ouvidos zunindo e o desgraçado deixa-se cahir sobre um banco ou sobre a icama, alheio á familia, a tudo, a sí mesmo; nos periodos de acalmia o desditoso homem, sempre mais ou menos sujeito aos phenomenos referidos, não tem animo para nada, não tem amor ás suas cousas, tem preguiça le fallar e até de pensar.

Este, meus senhores, é o Jeca Tatú, creado na imaginação de Monteiro Lobato e divulgado pela palavra de Ruy Barbosa.

No Brasil, como no resto da America, na Asia, na Africa as terriveis perturbaçōes da uncinariose, são provocadas, não pelo ancylostomo mas por seu "irmāo" o necator americanus. A molestia é a miesma ancylostomose européa, identico é o desenvolvimento dos vermes seus provocadores, igual é o systema de ataque ao homem.

S6 o microscopio reyela as differenças entre os dous vermes. Estas differenças estão no armamento de suas boccas; o ancylostomo tem dous pares de dentes ganchosos, duas pontas livres e uma lamina adherente: o necator arma-se, de duas laminas cortantes equivalentes aos ganchos do outro, e a sua lamina dorsal é livre, não soldada e saliente. São estas as principaes differenças morphologicas entre os dous agentes productoręs da uncinariose, cuja prophylaxia constitue um grave problema, pelo valor que representa, pela extensão que attinge, exigindo grande pertinacia e pelo relativo desrespeito que traz a certas commodidades pessoaes. Arrostemol-o todavia, que é PRO-PATRIA.

As larvas do necator vivem no solo, penetram pela pelle das plantas dos pés descalços. Pois bem; é difficil conseguir-se que as populações ruraes andem sempre calçadas de modo a evitarem a penetração das larvas; não esqueçamos o conselho, demol-o de boa vontade ao mesmo tempo que tratemos dos individuos infestados. Prohibam-se as evacuações sobre o solo, para o que as Municipalidades devem tornar obrigatoria aos proprietarios de casas e fazendas, onde não houver rêde de exgottos, a construção de fossas estanques. Espalhem-se fossas no perimetro da fazenda, de distancia em distancia ao longo das estradas de rodagens, medidas que podem ser effectuadas mediante accondo entre fazendeiros e as municipalidades visinhas.

Por fim, multe-se todo aquelle que for pilhado infringindo as disposições elaboradas e revertam-se estas multas em beneficio dos serviços prophylaticos.

Quanto ao tratamento, muitos têm sido preconisados e, segundo informes do Dr. Arthur Moses, do Instituto de Manguinhos, o Naphtol beta é o mais manejavel e mais economico, custando o tratamento de cada opilado, apenas 40 réis.

Entretanto, ficará ao alvitre do medico que, porventura, fôr investıdo das funções saneadoras, utilisar-se do methodo curativo que melhor lhe parecer.

\section{PALUdismo}

E' uma affecção produzida por um protozoario, o plasmodio, que se assesta nos globulos vermelhos do sangue, para onde é enviado por meio da picada do "mosquito prego" da familia dos anophelineos. Ha 3 
especies de plasmodios productores da paludismo; a que produz a febre terçan benigna, plasmodio vivax; a terçan maligna, plasmodio falciparum e a febre quartan, provocada pelo plasmodio malaria. Differenciam-se as febres pelos intervallos dos accessos; a benigna, mais commum entre nos tem intervallos de 48 horas, a quartan de 72 horas e a tercan maligna, tem intervallos de 24 horas.

Qualquer que seja a especie de protozoario paludico devemos considerar a molestia como unica, sem variante, porque a consideramos sob o pontu de vista de causadora de degeneração do individuo e prejulzo a nacionalidade e não como causamortis.

Excuso-me, para não vos fatigar demais, de descrever aqui o cyclo evolutivo do plasmodio, o modo porque elle é transfugado, da saliva do anopheles para o sangue do homem. De todo um complicado circuito resulta a tremenda molestia, altamente depauperadora do povo e vastamente espalhada pelo nosso Estado, principalmente pelo Nordeste, Noroeste, Centro e Sudoeste.

Havia outr'ora zonas limpas de paludismo; hoje, muitas destas estão invadidas, porque consentimos no alatramento do mal por intermedio de mosquitos, ao passo que picavam individuos sadios depois de estarem infectados por sangue paludico; não cuidamos de tratar os doentes, abandonamos os mosquitos na sua obra de devastação humana.

A prova deste triste facto, retiro-a dos dados da Repartição de Demographia Sanitaria do Estado; em 1913 falleceram $\mathbf{3 0 4}$ paludosos; em 1914, 815; em 1915, 1632, em 1916, 1410 e em 1917, 2043 :

A progressão caminha avassaladoramente e se deixarmos o paludismo entregue a si mesmo veremos dentro de não muitos annos, a horripilante invasão, o espectaculo indiano do exterminio annual de milhões de individuos. Poupemos aos nossos desventurados patricios os horrores da molestia e as tristezas infindas que a succedem. Tenhamos piedade, ao menos, dos que ainda não adoeceram, dos que estão ainda reservados para o sacrificio inglorio da morte por paludismo, no fundo do sertão, sem uma consolação trazida por uma tentativa sequer de tratamento. Poupemol-os ás agruras infinitas que lhes dá o depauperamento gradativo, quasi irremediavel; poupemol-os aos horrores que provam a chegada do calefrio, quando os desventurados homens, angustiados, empallidecidos, dobram-se, recurvam-se sobre si mesmos como que á procura de calor que crêm disperso pelo corpo, repuxando para cima de si quanta roupa encontrem ao alcance da mão; quando imploram com os labios trementes que lhes dêm bebidas quentes, alcoolicas, para terem a illusão de calor. Hora e meia depois, os paludicos soffrem do mesmo modo por motivo opposto a este. Hora e meia mais tarde, quando cessou o calefrio, sobrevem o periodo de calor, quando os infelizes maleitosos se desnudam, sob a sensação mortificante de temperatura excessiva, a pelle a escaldar, a garganta secca, os olhos fulgurando avermelhados, a voz de asphyxiado supplicando agua, agua bastante para molhar os labios resequídos, para diminuir o tormento da febre: gradualmente, pouco a pouco, cede a alta tempratura lugar á tmperatura normal; ao fim de muitas horas, quando parece que o soffrimento cessou, os miseros doentes entram no terceiro periodo, no periodo da sudação. Apoz o escaldamento, persistindo ainda a prostação que elle produzio, o paludoso se põe a suar, a se esvair em suores abundantissimos que, chegando por todos os poros alagam a pelle dando-lhe desagradabilissima algidez. Ao fim de 4 horas cessou tudo; o doente perdeu alguns milhares de globulos vermelhos, acha-se abatido, sem animo para nada, moralmente aniquilado porque prevê para ahi a dous dias a repetição dos soffrimentos experimentados. Vae trabalhar carregando comsigo um mal estar indescriptivel. 
Previnamos, misuls senhores, a expanisão do paluldismı, recorrendo aos meios imais exequiveis. Ponhamos the llaldo o anistocratico syste. ma de portas e janellas guarneicidas ide finas telas de arame; a dispersão da nossa população desaizonsellha o iseu uso.

Para se impedir a reproldulcçãc ldos mosiquitos transmlissores, emquanto 'se trate da população doente, destruam-se os seus focos, os seus "haibitat", pantanos e poças the agua, aguas eisitagnaudas em ireservatorios etc. A drenaig $\epsilon \mathrm{m}$ dos paues té tambem imeidilda muito dispen'diosa; mais vale, a municipalidade ideterminar a plantação ide eucalyptos ineistas zonas de terrenois humildos. Ass margens idos rios, idevem ser trattadias die maneira que, quanido se idê a vasantte ap.oz as en chentes, nāo haja a formaçāo de depositos de agua. O ponto leapital da campanha contra o paluldismo está em se impiedir que os moisquítos vehiculem os flasmoldios, e isto ten'to mais se lconseguira quanto mais sie reduzir o numero dos portadores ido protozoario. Em outras palavras, tratemos ldos paluidados, impedindo que os iseus plasmoldios sejam transporitaldos pello molsquito para um homem ainida são.

As Municipalidades, auxiliadas pelos poderes estaduaes e federaes, poderāo se encarregar da distribuiçāo gratuita do especifico - o quinino - ás populações pobres e doentes. Milhões de brasileiros voltarāo ao trabaliho, tornando-se, ao contrario do que eram, outros tantos individuos uteis a si e ao seu povo.

\section{TUBERCULOSE}

A pesste branca, que mata lemtamente, nunca ou lquasi nunca roukanıdo a esperança la sua prasa, a qual, ıdepois ıde calda dia ide molelstia, tem a illuisão de esitar mellhoran/do, a peste branca que solajpa familias inteiras, destruinda gente forte, icreando igente fraca vestá a exigir que sle the poniha á frente um obstaculo que sofireie a furia com que se propaga actualmente.

Elm 1914-2660; $\epsilon$.m 1915-2638; em 1916-2576; 'em 1917-2822 rexistencias foram stacrificaldas no nosso Estado, naturallmente depois de orientanem muitiss.imoss ongainisimos, para o mesmo posto die mantyrio, o que é ide toł lo provavel, porquie a tulberculose lé mollestia itransm:ssivel e de facil disseminaçāo entre nos.

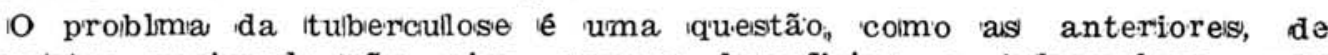
caralcter naciomail; não visa apenas beneficiar $\alpha$ tuberouloso, mas tambm a sua idescenliencia e os seus icircumistanites. Falla ida população inteira, antels idıe se referir ao cildadão.

A, sua prophyllaxia deve ser fieita por ldifferentels falces; eldulcação do porvo, fiscalisação dia alimentação popular, principalimente a infantill, guerra ao alicool, toreação de ldispensarios e isanatoriols para assisistencia aos tuberculosos. Deve ser assim feita para que possa surtir os effeitos idesejados, no espaço iminimo ide temipo.

Municipios congregaidos idervem tormar a isi, quanto anites, a campanha anti-tuberculose, afim idie que, pelo imenos, se reiduza o obituario desta terrivel moilestia.

Não se podie consentir ma monte prematura de mlillhares de compatricios, sem, nem ao menos, 'tenitar-ise impiedil-a.

A leppra, talivez porque iseja molestia reppulgnanite, já encontrou nos poderes publicos o solcicorro que se lhes peidia com tanta insistencia.

Entretanto, o numero de tuberculosos, sendo em muito, superior ao dos morpheticos, salvante as particulares, ainda não houve iniciativas que combaitessem o insidlioso inimigo, que ataca pela allimentação proveniente de animaes tulberculosos (icarne e leite), pelo icontagio que 
conjuge tuberculoso traz ao outro e transmitte aos filhos, seja de modo directo, seja indirectamente; pela promiscuidade dos operarios nas fabrica's mal conistruidas, pela occuppação immieidiaita e diesicuildada de cassas anteriormentie olccupadias ıpor tubericulosols. Allém das ccindições climatericas, consequencias da situação gecographica tdo nosso Eistado,

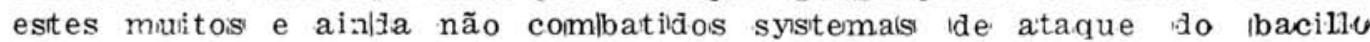
ao homem contam colm um grande numero de icircumstanicias, que os facilitam diminuindo a defiesa organica, reduzindo a resistencia p'essoal; jâ vos fallei do largo uso too allicooll; ido empobreicimento do physico de nossa gente cidadan e rural, da sua inconsciencia do perigo; da miá alimentaição geralmente usaida por ella.

Cuidemos destes factos, reduzamos as suas proporções e parte do ca minho terá sido feita; a outra parte, preenchel-a-á o systema hospitalar adequado. Constróe-se agora, por iniciativa de todos os municipios do Estado. em Mogy das Cruzes, um grande asylo para leprosos; porque se não ha de fazer, pelo mesmo processo economico para todos e para todos proveitosio, a mesma obra em favor dos tuberculosios, victimas, repito, muito mais numerosas do que os desventurados morpheticos e como elles, tão infelizes?

Cotizem-se as Municipalidades e construam sanatorios e dispensarios que beneficiem a legião daquelles que trazem, lavrado na sua sentença, quasi sempre, de morte, o castigo com que muitos dos seus semelhantes, indefesos, serão profundamente attingidos.

\section{SYPHILIS}

Não fôra a extensão que minhas palavras estão ganhando a este flagello, mereceria o meu commentario descolorido e bem intencionado. A syphilis, responsavel por um grande numero de debeis congenitos; pela nati-mortalidade, pelos innumeros disformes, e principalmente pela chusma de alienados, sejam maniacos, epilepticos, hystericos, melancholicos, neurasthenicos que povoam os manicomios depois de, por falta de lugares, percorrerem os postos policias ou vararem sem norte pelas ruas, a syphilis o terrivel morbo que victima tanta gente, não pode passar sem uma referencia e sem ser apontada como necessitada de medidas repressivas, bem represntadas, senão exclusivamente symbolisadas pelo tratamento especifico.

O recurso mais pratico que ha, para o combate a lues é a installaçāo, junto aos hospitaes, de postos de tratamento e de prophylaxia, sem remuneração, como já os tem o Centro Academico Oswaldo Cruz, da Facúldade de Medicina e Cirungia de são Paulo.

Senhoras alumnas: em vossas māos fidalgas qu eeu beijo respeitoso e agradecido, está o porvir da nacionallaade brasileira, no capitulo referente á mentalidade e ao civismo. Vos sereis as primeiras preparadoras das futuras almas e das futuras intelligencias de que nos orgulharemos mais tarde. Sereis as primeiras guias das vindouras e mais proximas gerações do nosso povo. Eis o papel que vos está destinado e que desenvo1vereis nas cidades e nos campos brilhantissimamente. Vós e as vossas collegas de outras escolas, apprehenderão dentro em pouco, o destino de uma terra que, se foi a ardorosa ambição dos nossos aniepassados, é o nosso justificado orgu'liho. As palavras que ouvistes, despidas de novidade e poesia, mal esicriptas entre exames e incidentes escolares, representam, embora mediocremente, um cathecismo por onde devem rezar, quantos desejam a ventura propria, nunca mais do que um reflexo e um atomo de felicidade geral, da sorte da nação. O que de mim ouvistes é uma realidade muitas vezes desvirtuada pelo graçolismo de alguns dos 
nossos compatriotas e outras vezes explorada, pela animosidade extrangeira. Encaremol-a com serena energia: dentro de alguns lustros é que ella, perseverando a reacção iniciada, se nos apresentará modificada. melhorada. A realidade daquelle dia não terá os tons cinzentos de agorá, será de cõr e aspecto suaves. Fallei-vos porque em dias proximos ireis ser elevados expoentes de cultura, ouvidos e acatados pelos que vos cercarem. A palavra de um profesisor tem entre o povo grande respeito, profunda consideraçāo sem os laivos de terror que infundia outróra. $\mathbf{E}$ tida como conselho de amigo e não como imposição de senhor. Brevemente sereis conselheiras e foi por isto que vos fallei. Cuidae sacerdotisas de excelso bem, dos vossos alumnos como se elles fossem vos mesmas. Daelhes introducçāo, dae-lhes coragem civica, dae-lhes o vosso amôr, porque é de amôr que se alimentam as alması bôas e as almas das creanças nunca são más. Incuti-lhes nos espiritos ainda virgens da maldade e da malicia, as ideias de Povo e Patria, de Familia e Homem e as doutrinas da Hygiene do Espirito, de Saude e do Caracter, verdades que fazem o filho extremoso, o pae dedicado e o bom cidadāo. Fazei-lhes incansavelmente a apologia da instrucção, do asseio, do contralcoolismo, dos bons costumes moraes, da educação militar, do dever do voto, do nacionalismo enfim. Comvosico, na escola primaria a creança, botão risonho do canteiro Patria, ouvirá tudo isto, sem o sorriso mordaz, envenenador, que entreabre os labios de muita gente de mais edade, á mesma audiçāo. $\mathrm{Na}$ escola primaria a creança guardará pouco, e pouco entenderá do que lhe disserdes: mas isto nāo importa - porque a sua chegaida nas escolas secundarias os seus professores repetirāo o codigo de cidadania e suas ideias se tornarão mais claras e mais vigorosas. Annos' depois, terminado o curso secundario, nas escolas superiores, por entre aulas de mathematicas, ou de jurisprudencia, de sciencias medicas ou de quaesiquer outras, volvendo a ouvir a predica nacionalista, o moço, entāo fructo $\in \mathrm{m}$ vias de maturaçāo - gravará no seu espirito, indelevelmente, todo o rictual da seita de amôr á terra natal e mais tarde será o seu bom semeador, o acolyto convicto dos saudosos apositolos de revigoramento do nosso patriotismo - Olavo Bilac e Miguel Pereira. Por amôr ao Brasil e s6 por amôr ao Brasil é que nos empenhamos nesta cruzada, magnifica como aquella em que se bateram os ohristāo para a conquista aos mouros, da Terra Santa e dos santos legados de sua igreja. Elles, por sua religião dispenderam todas as forças do seu corpo, todas as energias de sua fe. nos, por nossa patria, empregaremos todos os nossos esforços, todos os nossos recursos até a ultima systole do nosso coraçāo. 